\title{
A 2-year retrospective review of the effect of cigarette smoking status on the histological cell types of lung carcinoma in the Western Cape
}

\author{
A S Pellizzon, MB ChB, MMed (Int), FCP (SA); C F N Koegelenberg, MB ChB, MMed, FCP (SA), FRCP, Cert Pulm (SA), PhD; \\ E M Irusen, $\mathrm{MB}$ ChB, FCP (SA), PhD
}

Division of Pulmonology, Department of Medicine, Stellenbosch University and Tygerberg Academic Hospital, Cape Town, South Africa

Corresponding author: A S Pellizzon (adrianojudith@yahoo.co.uk)

Background. Cigarette smoking is variably associated with the various histological cell types of lung cancer. The primary aim of this study was to analyse various strengths of association between the common histological cell types of lung cancer and smoking in a Western Cape population. The secondary aim examined whether an association exists between scar carcinoma and smoking.

Methods. We retrospectively analysed the records from 386 patients over a 2 -year period. Both smokers and non-smokers were subdivided and analysed as two groups, which included those with non-small cell and small cell lung cancer. Smokers and non-smokers were also analysed separately according to the presence or absence of lung scarring.

Results. In total, $94.3 \%$ of all patients with lung cancer were current or past smokers. There was a disproportionately higher number of patients with adenocarcinoma who were non-smokers compared with all the other cell types $(p=0.01)$, whereas patients with squamous cell carcinoma were more likely to be smokers $(p=0.05)$. Although the vast majority of patients with and without lung scars were found to be smokers ( $96.4 \%$ v. $93.7 \%$ respectively), there was no statistically significant difference found between these two groups ( $p=0.43$ ).

Conclusion. In a Western Cape population, patients with adenocarcinoma were more likely to be non-smokers, while those with squamous cell carcinoma were relatively more likely to be smokers. No clear association between scar carcinoma and smoking status was found.

S Afr Resp J 2015;21(2):23-28. DOI:10.7196/sarj.8441

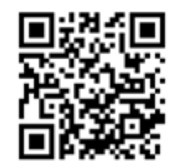

Pulmonary malignancies are significant to South Africa (SA), with Bradshaw et al. demonstrating that cancer of the trachea, bronchi and lung ranks 17th among the top 20 causes of premature mortality burden in males. ${ }^{[1]}$ Lung cancer, in 80 - 90\% of cases, is attributed to smoking and a smaller proportion $(10-20 \%)$ is attributed to occupational exposure to agents such as asbestos and silica. ${ }^{[2-4]}$ Thus due to the high prevalence of cigarette smoking among people older than 15 in SA (27.1\% in 2000), lung cancer remains a major public health concern in this country. ${ }^{[5]}$

Cigarette smoking is often intimately associated with all the histological types of lung cancer but the strength of association tends to differ with each individual variant. ${ }^{[6]}$ Data from the USA have shown a decreasing incidence of squamous cell carcinoma (SCC), small cell lung cancer (SCLC) and large cell carcinoma (LCC), while there has been a moderate increase in the incidence of adenocarcinoma (ADC). ${ }^{[7]}$ Khuder $^{[6]}$ demonstrated that all histological types were significantly associated with cigarette smoking, with SCLC displaying the strongest overall relationship followed by SCC. ADC appeared to have the weakest overall relationship. ${ }^{[6]}$ Research performed by Yang et al. ${ }^{[8]}$ and others, ${ }^{[9]}$ also documented that more peripheral cancers (ADC and LCC) show weaker associations than more central tumours (SCLC and SCC). Non-smokers appear to have a greater proportion of ADC when compared with the other histological types, and this may suggest that other factors (genetic, occupational, environmental) are involved in its aetiology. ${ }^{[10-16]}$

A controversial topic is the relationship between scarring of the lung and the development of lung cancer. ${ }^{[17]}$ Scar carcinoma (SC) of the lung is a clinical entity that was first described by Friedrich ${ }^{[18]}$ and Rossle ${ }^{[19]}$ as a group of lung cancers that originated around peripheral scars in the lung. Owing to further research performed in the 1940s, there was a subsequent evolution in the understanding of SC and the following clinical features were then thought to make the diagnosis of SC more likely: the tumour is peripherally located with a size of less than $3 \mathrm{~cm}$ in diameter, upper-lobe predominance, more commonly found in males, and usually of ADC histological subtype ${ }^{[20-22]}$ A large cohort analysis of the prostate, lung, colorectal and ovarian cancer screening trial demonstrated a clear correlation between scar presence and the development of a carcinoma. ${ }^{[23]}$

Cigarette smoking has long been known to be associated with chronic lung destruction and the development of lung cancer. ${ }^{[17]}$ The chronic inflammatory state induced by cigarette smoke eventually results in DNA mutations along with excessive bronchioalveolar stem cell proliferation, which is thought to cause the development of lung carcinoma. ${ }^{[24,25]}$ Of particular interest is the possible link between SC and smoking. Research published by Auerbach et al. ${ }^{[26]}$ suggested a lack of association between smoking and SC in their study population.

With the above in mind, and data of this nature lacking in the Western Cape, we performed a retrospective study with two objectives. The primary objective was to analyse various strengths of association between the common histological cell types of lung cancer and cigarette smoking in our population. The secondary objective was to examine whether an association exists between SC and smoking, with our hypothesis being that no such association exists. 


\section{Methods}

Study population

Tygerberg Academic Hospital is situated in Cape Town, SA. It comprises 1380 beds and is one of two tertiary hospitals serving approximately three million people from various drainage areas. We retrospectively identified 424 patients with lung cancer that were presented at our weekly lung cancer board meetings from 1 January 2010 to 31 December 2011 (Fig. 1). Individuals were then excluded if no data could be found regarding a smoking pack year history ( 25 participants) or if either the staging computed tomography (CT) scan or tissue diagnosis were incomplete (13 participants). Cases of pleural malignancy, such as mesothelioma or secondary pulmonary malignancies, were excluded from the analysis. The Stellenbosch

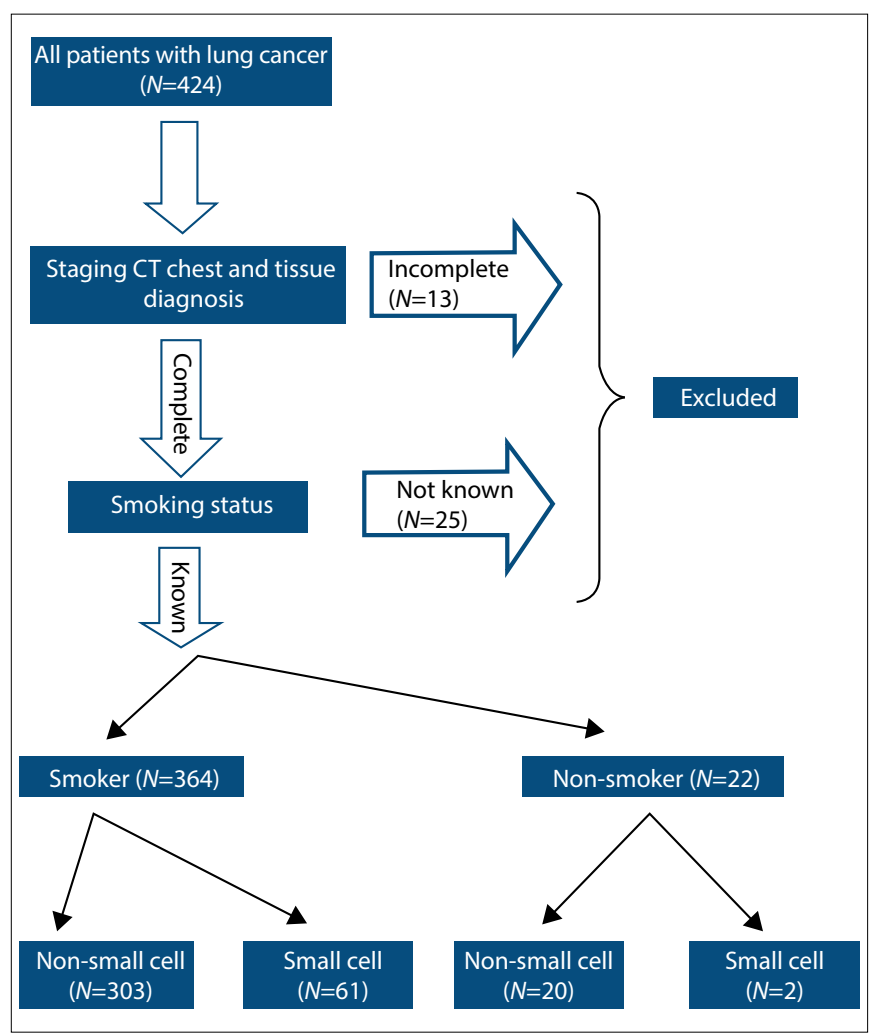

Fig. 1. Study population distribution according to smoking status and lung cancer cell type.

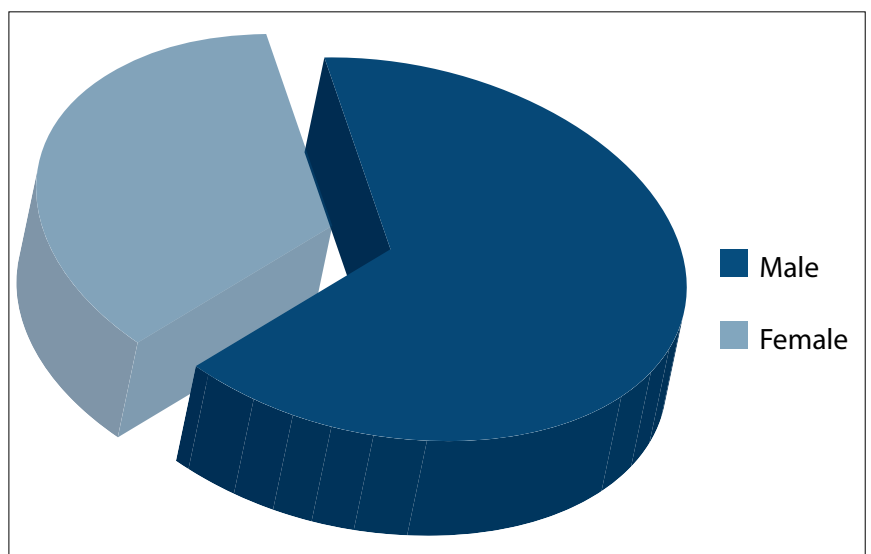

Fig. 2. Gender distribution of the study population.
University Human Research Ethics Committee granted approval for the study (study number S13/04/078) and a Chief Medical Superintendent of Tygerberg Academic Hospital granted access to patient medical records so as to collect the necessary data.

\section{Data collection}

From the medical records of the study population, we collected basic demographic data as well as the histological cell type and the presence of a possible SC. Tumour, node and metastasis (TNM) staging, as well as cigarette smoking status were specifically documented.

Telephonic contact was made with various patients and their next of kin when no data could be found from our folders. The diagnosis of tissue subtypes was based on cytology or on histology done on adequate samples at a later stage. The diagnoses were further verified by ancillary immunohistochemistry or immunocytochemistry techniques in most cases. After exclusions, our study population $(n=386)$ was split into smokers and non-smokers. Smokers were defined as those who had smoked a minimum of at least 5 pack years while non-smokers were defined as those who had never smoked or who had smoked less than 5 pack years.

We then sought to separately determine how many smokers and nonsmokers had non-small cell lung cancer (NSCLC) v. SCLC. The NSCLC group was further subdivided into common histological cell types to allow for added statistical analysis. Finally we determined how many patients with a recognised scar were smokers versus non-smokers and likewise the same analysis was completed for those patients without a scar. A scar was identified as an area of pulmonary fibrosis situated in any area of the lungs in a patient with a diagnosis of primary lung carcinoma. All diagnosed cases of bronchogenic carcinoma were staged radiologically according to the staging system set out by the Union Internationale Contre le Cancer in 2002 for lung cancer. ${ }^{[27]}$

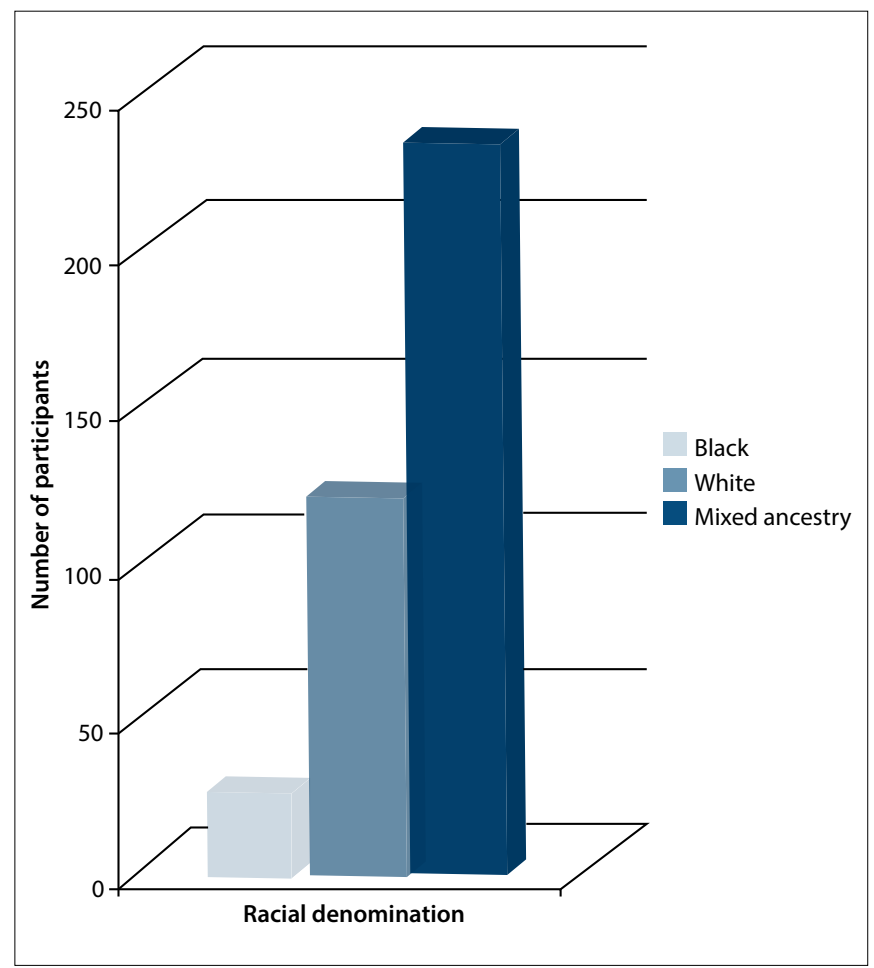

Fig. 3. Racial distribution of the study population. 


\section{Statistical analysis}

Statistical indices utilised for this assignment included averages, ranges and standard measures of statistical significance ( $p$-values). All $p$-values were calculated with Fisher's Exact Probability test, and in one case a $p$-value was calculated with the $\chi^{2}$ test (Yates corrected). All statistical analysis was completed using VassarStats (USA).

\section{Results}

We included 386 participants, with a total of 229 (59.3\%) males and 157 (40.7\%) females (Fig. 2). The average age for the male participants was 59.4 (range 30 85 ) years and the average age for female participants was $61.4(36-88)$ years. The racial demographics demonstrated that the study population was composed of 237 (61.4\%) participants of mixed ancestry, 122 (31.6\%) white participants and 27 (7\%) black participants (Fig. 3).

ADC predominated with 156 (40.4\%) patients demonstrating this cell type at diagnosis. SCC was diagnosed in 93 (24.1\%) participants, LCC was diagnosed in $70(18.1 \%)$ participants and SCLC was diagnosed in $63(16.3 \%)$ participants. A small category of NSCLC diagnoses not related to the cell types above accounted for 4 (1\%) participants. The four cases included one case each of pleomorphic carcinoma, pleomorphic carcinoma with osteoclast giant cells, a solitary fibrous tumour, and an anaplastic carcinoma (Fig. 4).

There were 364 (94.3\%) participants who smoked, while 22 (5.7\%) did not. There was a disproportionately higher number of patients with ADC who were non-smokers compared with all the other cell types (15/22 non-smokers had ADC; $p=0.01$ ), whereas patients with SCC were more likely to be smokers (90/93 patients with SCC were smokers; $p=0.05)$. Patients with ADC smoked on average 31.6 pack years compared with patients with SCC, who smoked on average 32.4 pack years. There were no statistically significant differences between smokers and non-smokers among the patients with LCC, other NSCLC or SCLC (Table 1).

Analysis of patients with lung scars demonstrated that $81(96.4 \%)$ of them were smokers while 3 (3.6\%) were not. Of those patients without lung scars, $283(93.7 \%)$ of them smoked while 19 (6.3\%) did not. Patients without lung scars had smoked for

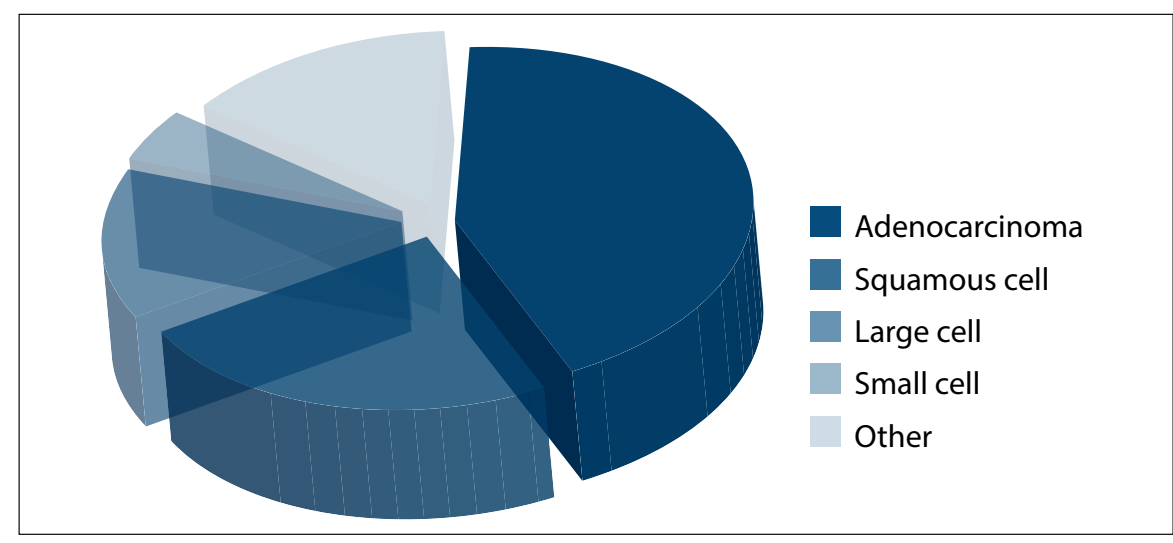

Fig. 4. Study population distribution according to histological diagnosis.

Table 1. Differences in lung carcinoma tissue diagnoses among the study population

\begin{tabular}{|c|c|c|c|c|}
\hline Cell type & Smokers $(n)$ & $\begin{array}{l}\text { Pack years } \\
\text { (mean) }\end{array}$ & $\begin{array}{l}\text { Non- } \\
\text { smokers }(n)\end{array}$ & $p$-value ${ }^{*}$ \\
\hline \multicolumn{5}{|l|}{ Non-small cell } \\
\hline Adenocarcinoma & 141 & 31.6 & 15 & $0.01^{\dagger}$ \\
\hline Squamous cell & 90 & 32.4 & 3 & 0.05 \\
\hline Large cell & 68 & 40.1 & 2 & 0.40 \\
\hline Other & 4 & 55.0 & 0 & 1.00 \\
\hline Small cell & 61 & 37.6 & 2 & 0.40 \\
\hline \multicolumn{5}{|c|}{${ }^{*}$ Fisher's Exact Probability Test, except $\dagger$. } \\
\hline
\end{tabular}

Table 2. Differences between patients with lung scarring and those without

\begin{tabular}{lllll}
\hline & Smokers $(\boldsymbol{n})$ & $\begin{array}{l}\text { Pack years } \\
(\mathbf{m e a n})\end{array}$ & $\begin{array}{l}\text { Non- } \\
\text { smokers }(\boldsymbol{n})\end{array}$ & $\boldsymbol{p}$-value \\
\hline SCAR & 81 & 31.9 & 3 & 0.43 \\
No SCAR & 283 & 35.4 & 19 & 0.43
\end{tabular}

more years on average (35.4 pack years) than patients with lung scars (31.9 pack years). However, no statistically significant difference between smokers and non-smokers was found in both groups (Table 2).

Only $22(6.8 \%)$ patients with NSCLC had early-stage lung cancer (stages I $(n=11)$ and II $(n=11))$. There were $18(5.6 \%)$ patients with stage IIIA disease and $83(25.7 \%)$ with stage IIIB disease. The majority of cases (200 (61.9\%)) of NSCLC had metastatic disease at presentation (Table 3). Among patients with SCLC, $13(20.6 \%)$ were found to have limited disease, while 50 (79.4\%) had extensive disease at presentation (Table 3 ). Of the $53(13.7 \%)$ patients (NSCLC and SCLC) with potentially operable disease only 20 (5.2\%) of them underwent surgical tumour resection.

\section{Discussion}

We found a disproportionately higher percentage of patients with ADC to be nonsmokers compared with the other cell types, whereas patients with SCC were more likely to be smokers. We again demonstrated that ADC has surpassed SCC as the most common histological cell type of lung cancer in the Western Cape. ${ }^{[28]}$ Among smokers and non-smokers, we found no statistically significant difference between those with lung scars and those without. Finally, as has been previously documented ${ }^{[28]}$ we demonstrated that the majority of patients with NSCLC and SCLC had an advanced level of disease at presentation.

ADC in our study population was the most common cell type found and this appears to be similar in the USA, where increasing 
Table 3. Summary of the TNM radiological staging of the study population

\begin{tabular}{llllll}
\hline Staging & Adenocarcinoma & Squamous cell & Large cell & Other NSCLC & $\begin{array}{l}\text { Small } \\
\text { cell }\end{array}$ \\
\hline IA & 1 & 1 & 0 & 0 & - \\
IB & 4 & 4 & 0 & 1 & - \\
IIA & 1 & 0 & 0 & 0 & - \\
IIB & 6 & 2 & 2 & 0 & - \\
IIIA & 9 & 5 & 4 & 0 & - \\
IIIB & 40 & 29 & 13 & 1 & - \\
IV & 95 & 52 & 51 & 2 & - \\
Limited & - & - & - & - & 13 \\
Extensive & - & - & - & - & 50
\end{tabular}

incidences of $\mathrm{ADC}$ are reported. ${ }^{[7]} \mathrm{ADC}$, along with LCC, is more peripherally situated than SCLC and SCC. The higher incidences of ADC worldwide could possibly be explained on technical advancements made in fine-needle aspiration, ${ }^{[29-32]}$ computerised scans, ${ }^{[33]}$ video bronchoscopy, ${ }^{[34]}$ immunohistochemistry and mucin staining, ${ }^{[35]}$ which all improve the diagnostic yield of these peripherally situated tumours. Of particular interest in our study was the relation of histological cell types to smoking. Our data suggested that patients with ADC in this study population make up a disproportionately higher percentage of non-smokers, and this finding appears to be consistent with other research done in this field. ${ }^{[10-16]}$

There have been suggestions that changes to cigarette design in the last few decades could help explain the rising incidence of ADC. ${ }^{[36]}$ However, this is not enough to explain why non-smokers in our setting developed ADC more frequently than other cell types of lung cancer. A possible explanation in our country includes possible indoor air pollutants as the offending agents. A large proportion of SA households do not have full-time electricity and so have to rely on fossil fuels (coal and wood) to heat the house and to cook food. The liberation of small coal dust particles in the process of burning these materials may be inhaled deeply into the distal airways, and prolonged exposure to this over time may incite the development of ADC. Furthermore, there may be carcinogens in our working environments and passive second-hand smoke exposure that could also cause ADC more frequently in non-smokers. Genetic determinants and predisposition cannot be ruled out. However, more research is needed to delineate exactly which gene, if any, is involved.

Of further interest from our study is that patients with SCC are more likely to be smokers. Other studies have also found this trend, demonstrating that SCC (more centrally located) tends to have an overall stronger relationship with cigarette smoking than does ADC (more peripherally located). ${ }^{[6,8,9,37,38]}$ Our data found that on average patients with SCC smoked more than patients with $\mathrm{ADC}$ and this is further supported in the literature, where there appears, in general, to be a stronger dose-response relationship between centrally located tumours like SCC and cigarette smoking than with tumours situated more peripherally such as ADC. ${ }^{[9]}$ One possible explanation for the closer association between SCC and smoking is nicotine. ${ }^{[39]}$ Nicotine, a common ingredient in most cigarettes, is not only the addictive agent but is also a known carcinogen. In a study performed by Brown et al. ${ }^{\left[{ }^{[3]}\right.}$ nicotine was found to increase $\alpha 7$ nAChR mRNA levels and transcription in SCC cell lines that ultimately promoted lung cancer proliferation. There is uncertainty at this point as to whether nicotine has exactly the same effect on other cell types of lung cancer.

With specific reference to the relationship between SC and smoking, we found no significant difference in our study population between smokers and non-smokers (both with scars and without). Our data are therefore similar to other studies, specifically that performed by Auerbach et al. ${ }^{[26]}$ who found a lack of association between smoking and SC. A possible explanation is that atypical epithelial cells exist around some scars that later undergo unregulated proliferation with the development of metaplastic and then neoplastic cells, ${ }^{[40-45]}$ which may occur irrespective of carcinogen exposure from smoking. There may be a genetic blueprint within a scar that gives it the ability to become neoplastic. More research is needed to uncover the most likely aetiology of SC and also identify its exact relationship to various environmental exposures.

Advanced-level disease was found in the vast majority of our sample whether that be patients with NSCLC or SCLC. Furthermore, very few of our patients with potentially operable disease underwent surgery. Data from the UK National Lung Cancer Audit in 2009 found that the overall unadjusted proportion of patients who underwent surgical resection was approximately $11 \%$, with regional variations ranging from less than $5 \%$ to greater than $25 \% .{ }^{[46]}$ Other countries in Europe had much higher rates of resection, such as Italy $(24 \%),{ }^{[47]}$ the Netherlands $(20 \%)^{[48]}$ and Sweden (17.5\%). ${ }^{[49]}$ The group in the UK suggested that lower resection rates were due to diminished access to specialist thoracic surgeons. However, we believe our lower rates are owing to our own societal circumstances.

The vast majority of patients attending our hospital have impoverished socioeconomic circumstances as well as low levels of education, which tends to delay the presentation of patients with lung cancer to our specialist clinic. Transportation can be expensive and also unreliable, which further hinders access. The high prevalence of pulmonary tuberculosis in our setting (935 per 100 000), , ${ }^{[50]}$ also masks the diagnosis of lung cancer. For instance, patients with pulmonary tuberculosis and lung cancer often have similar symptoms, so patients may be initially treated inappropriately for tuberculosis when in fact they have lung cancer. The investigation done for tuberculosis at primary care level can often become protracted: waiting for results owing to a limited numbers of laboratories in the district and specimens getting lost on route. This means that patients with lung cancer get identified later than they should. Lastly, since tuberculosis has a myriad of possible radiological features, the clinician may be misled into thinking that a lung lesion is secondary to tuberculosis instead of investigating further for lung cancer. Korean data suggest that this problem is not isolated to SA, as they too have a high 
prevalence of tuberculosis. ${ }^{[51]}$ The Korean data found an average delay of 11.7 months in diagnosing lung cancer for similar reasons to those mentioned previously. ${ }^{[51]}$

We believe that our study has definite clinical application. Owing to the large number of females with lung cancer in our sample and their rising mortality rates in our country, more should be done by clinicians to try and inform females of this problem. Health education should begin at an early age in our communities and in our schools so as to prevent further increases in female mortality in later decades. More research is needed to understand the pathophysiology surrounding $\mathrm{ADC}$ of the lung in our setting and the environmental triggers that could lead to this disease. Simple public health measures, such as providing better electricity to poorer areas, may result in less reliance on fossil fuels for daily living and thereby limit exposure to possible harmful carcinogens in these fuels. Since most patients with SCC present many years after smoking is initiated, we need to educate our communities at an early age so as to limit smoking exposure. More audio-visual media should be made available in our clinics, schools and in major public places to discourage smoking. Furthermore, our data can also help to inform policy makers that are involved with tobacco regulation.

\section{Study limitations}

The retrospective nature of our study had inherent limitations. Recall bias was introduced into our study when contacting the next of kin in order to obtain the necessary information of those patients who have died. We were also unable to speculate on the aetiology of lung cancer in our study population owing to multiple confounders that may exist (e.g. occupational exposures). Finally, due to selection bias we were unable to generalise our findings to the SA population at large, since certain ethnic groups (e.g. rural blacks and Asian individuals) were underrepresented in our study population.

In conclusion, we found that more than $90 \%$ of all patients with lung cancer were smokers. In patients with ADC, there were a disproportionately higher percentage of non-smokers compared with the other cell types, whereas patients with SCC were more likely to be smokers. There was no statistically significant difference found between smokers and non-smokers, both in the group with lung scars and in the group without. Future research is needed for a better understanding of the aetiology of both the common histological cell types of lung cancer and SC in the Western Cape.

\section{Authors' contributions}

Dr AS Pellizzon: conceived and designed the study. He analysed and interpreted data and then drafted and critically revised the manuscript. He approved the published version.

Professor CFN Koegelenberg: conceived and designed the study. $\mathrm{He}$ analysed and interpreted data and then critically revised the manuscript. He approved the published version.

Professor EM Irusen: conceived and designed the study and critically revised the manuscript. He approved the published version.

\section{References}

1. Bradshaw D, Groenewald P, Laubscher R, et al. Initial burden of disease estimates for South Africa, 2000. S Afr Med J 2003;93(8):682-688

2. World Health Organization International Agency for Research on Cancer. IARC monographs on the evaluation of the carcinogenic risk of chemicals to humans. Volume 34. Lyon; 1984.
3. Siemiatycki J, Richardson L, Straif K, et al. Listing occupational carcinogens. Environ Health Perspect 2004;112(15):1447-1459. [http://dx.doi.org/10.1289/ehp.7047]

4. Driscoll T, Nelson DI, Steenland K, et al. The global burden of disease due to occupational carcinogens. Am J Ind Med 2005;48(6):419-431. [http://dx.doi. org/10.1002/ajim.20209]

5. van Walbeek C. Recent trends in smoking prevalence in South Africa--some evidence from AMPS data. S Afr Med J 2002;92(6):468-472.

6. Khuder SA. Effect of cigarette smoking on major histological types of lung cancer: A meta-analysis. Lung Cancer 2001;31(2-3):139-148.

7. Davis WD, Lubin J, Ries L, et al. United States lung carcinoma incidence trends: Declining for most histologic types among males, increasing among females. Cancer 1996;77(12):2464-2470.

8. Yang CP, Gallagher RP, Weiss NS, Band PR, Thomas DB, Russell DA. Differences in incidence rates of cancers of the respiratory tract anatomic subsite and histologic type: An etiologic implication. J Natl Cancer Inst 1989;81(23):1828-1831.

9. Morabia A, Wynder EL. Cigarette smoking and lung cancer cell types. Cancer 1991;68(9):2074-2078.

10. Franceschi S, Bidoli E. The epidemiology of lung cancer. Ann Oncol 1999;10(Suppl 5):S3-6.

11. Barbone F, Bovenzi M, Cavallieri F, Stanta G. Cigarette smoking and histologic type of lung cancer in men. Chest 1997;112(6):1474-1479.

12. Wynder EL, Kabat GC. The effect of low-yield cigarette smoking on lung cancer risk Cancer 1988;62(6):1223-1230.

13. Lubin JH, Blot WJ. Assessment of lung cancer risk factors by histologic category. J Natl Cancer Inst1984;73(2):383-389.

14. Schoenberg JB, Wilcox HB, Mason TJ, et al. Variation in smoking-related lung cancer risk among New Jersey women. Am J Epidemiol 1989;130(4):688-695.

15. Xu ZY, Blot WJ, Xiao HO, et al. Smoking, air pollution and high rates of lung cancer in Shenyang, China. J Natl Cancer Inst 1989;81(23):1800-1806.

16. World Health Organization International Agency for Research on Cancer. IARC monographs on the evaluation of the carcinogenic risk of chemicals to humans. Volume 38. Lyon; 1986.

17. Bobba RK, Holly JS, Loy T, Perry MC. Scar carcinoma of the lung: A historical perspective. Clin Lung Cancer 2011;12(3):148-154. [http://dx.doi.org/10.1016/j. cllc.2011.03.011]

18. Friedrich G. Periphere lungenkrebse auf Boden Pleuranaher Nerben. Virchows Arch 1939;304:230-247 (Pathol Anat J).

19. Rossle R. Die Narbenkrebse der Lungen. Schweiz Med Wochenschr1943; 39:1200-1203.

20. Freant LJ, Joseph WL, Adkins PC. Scar carcinoma of the lung. Fact or fantasy? Ann Thorac Surg 1974;17(6):531-537. [http://dx.doi.org/10.1016/S0003-4975(10)65693-7]

21. Yokoo H, Suckow EE. Peripheral lung cancers arising in scars. Cancer 1961;14:1205-1215.

22. Bennett DE, Sasser WF, Ferguson TB. Adenocarcinoma of lung in men. A clinicopathologic study of 100 cases. Cancer 1969;23(2):431-439.

23. Yu YY, Pinsky PF, Caporaso NE, et al. Lung cancer risk following detection of pulmonary scarring by chest radiography in the prostate, lung, colorectal, and ovarian cancer screening trial. Arch Intern Med 2008;168(21):2326-2332. [http:dx. doi.org/10.1001/archinte.168.21.2326]

24. Kim CF, Jackson EL, Woolfenden AE, et al. Identification of bronchioalveolar stem cells in normal lung and lung cancer. Cell 2005;121(6):823-835. [http:dx.doi. org/10.1016/j.cell.2005.03.032]

25. Hecht SS, Hoffman D. Tobacco-specific nitrosamines, an important group of carcinogens in tobacco and tobacco smoke. Carcinogenesis 1988;9(6):875-884.

26. Auerbach O, Garfinkel L, Parks VR. Scar cancer of the lung: Increase over a 21 year period. Cancer 1979;43(2):636-642.

27. Union Internationale Contre le Cancer. TNM Classification of Malignant Tumours, 6th edition. New York: Wiley-Liss, 2002:272.

28. Aubeelack K, Koegelenberg CF, Bolliger CT, von Groote-Bidlingmaier F, Irusen EM Lung Cancer in the Western Cape of South Africa - urgent need to improve awareness and earlier detection. S Afr Resp J 2012;18(1):11-14.

29. Silver CE, Koss LG, Brauer RJ, et al. Needle aspiration cytology of tumors at various body sites. Curr Probl Surg 1985;22(1):6-67. [http://dx.doi.org/10.1016/00113840(85)90029-2]

30. Miller WE, Berquist TH. Percutaneous transthoracic needle biopsy. Semin Resp Med 1981;3(1):10-16.

31. Koss LG. Thin needle aspiration biopsy. Acta Cytol 1980;24:1-3. (editorial).

32. Lundgren R, Bergman F, Angström T. Comparison of transbronchial fine needle aspiration biopsy, aspiration of bronchial secretion, bronchial washing, brush biopsy and forceps biopsy in the diagnosis of lung cancer. Eur J Respir Dis 1983;64(5):378-385.

33. Wittenberg J. Computed tomography of the body. N Engl J Med 1983;309(2):1160-1165.

34. Ikeda S, Yanai N, Ishikawa S. Flexible bronchofiberscope. Keio J Med 1968;17(1):1-16

35. Marchevsky AM. Classification of lung tumors. In: Marchevsky AM, ed. Surgical Pathology of Lung Neoplasms. New York: Marcel Dekker, 1990;63-68. 
36. Wynder EL, Hoffmann D. Smoking and lung cancer: Scientific challenges and opportunities. Cancer Res 1994;54(20):5284-5295.

37. Yun YH, Lim MK, Jung KW, et al. Relative and absolute risks of cigarette smoking on major histologic types of lung cancer in Korean men. Cancer Epidemiol Biomarkers Prev 2005;14(9):2125-2130. [http://dx.doi.org/10.1158/1055-9965.EPI-05-0236]

38. Lee PN, Forey BA, Coombs KJ. Systematic review with meta-analysis of the epidemiological evidence in the 1900s relating smoking to lung cancer. BMC Cancer 2012;12:385. [http:dx.doi.org/10.1186/1471-2407-12-385]

39. Brown KC, Perry HE, Lau JK, et al. Nicotine induces the up-regulation of the a7-nicotinic receptor ( $\alpha 7$-nAChR) in human squamous cell lung cancer cells via the Sp1/GATA pathway. J Biol Chem 2013;288(46):33049-33059. [http://dx.doi.org/10.1074/jbc.M113.501601]

40. Raeburn C, Spencer H. A study of the origin and development of lung cancer. Thorax 1953;8(1):1-10.

41. Kitagawa M. Autopsy study of lung cancer with special reference to scar cancer. Acta Pathol Jpn 1965;15(2):199-222.

42. Chaudhuri MR. Primary pulmonary scar carcinomas. Indian J Med Res 1973;61(6):858-863.

43. Ripstein CB, Spain DM, Bluth I. Scar cancer of the lung. J Thorac Cardiovasc Surg 1968;56(3):362-370.
44. Balo J, Juhasz E, Temes J. Pulmonary infarcts and pulmonary carcinoma. Cancer 1956;9(5):918-922.

45. Berkheiser SW. Pulmonary infarction associated with lung cancer. Dis Chest 1965;47:36-41.

46. The NHS Information Centre. National Lung Cancer Audit 2009. http://www.hscic. gov.uk/catalogue/PUB02692/clin-audi-supp-prog-lung-canc-nlca-2009-rep.pdf (accessed 15 March 2013).

47. Imperator A, Harrison RN, Leitch DN, et al. Lung cancer in Teesside (UK) and Varese (Italy): A comparison of management and survival. Thorax 2006;61(3):232-239. [http://dx.doi.org/10.1136/thx.2005.040477]

48. Damhuis RA, Schütte PR. Resection rates and postoperative mortality in 7,899 patients with lung cancer. Eur Respir J 1996;9(1):7-10.

49. Myrdal G, Lamberg K, Lambe M, Ståhle E, Wagenius G, Holmberg L. Regional differences in treatment and outcome in non-small cell lung cancer: A population-based study (Sweden). Lung Cancer 2009;63(1):16-22. [http://dx.doi.org/10.1016/j.lungcan.2008.05.011]

50. Western Cape Government. World TB Day, 24 March 2012. http://www.westerncape. gov.za/news/world-tb-day-24-march-2012 (accessed 29 October 2013)

51. Kim II Y, Goo MJ, Kim YH, et al. Coexisting bronchogenic carcinoma and pulmonary tuberculosis in the same lobe: radiological findings and clinical significance. Korean J Radiol 2001;2(3):138-144. 